\title{
Differential Expression, Diagnostic and Prognostic Significance of Stathmin-1 and CD147 in Various Uterine Smooth Muscle Tumors
}

\author{
Expresión Diferencial, Diagnóstico y Significado de Pronóstico de \\ Stathmin-1 y CD147 en Diferentes Tumores del Músculo Liso Uterino
}

Nisreen Abu Shahin'; Ali Al-khader²; Manar Alsayed'; Duaa Aljarrah' \& Majd Khader'

\begin{abstract}
ABU SHAHIN, N.; AL-KHADER, A.; ALSAYED, M.; ALJARRAH, D. \& KHADER, M. Differential expression, diagnostic, and prognostic significance of stathmin-1 and CD147 in various uterine smooth muscle tumors. Int. J. Morphol., 37(1):311-318, 2019.

SUMMARY: Uterine smooth muscle tumors (USMT) are common, behavior-distinct gynecological tumors; including: leiomyoma (ULM), leiomyosarcoma (ULMS), and smooth muscle tumors of undetermined malignant potential (STUMP). Pre-operative distinction is difficult, thus diagnosis relies on histopathology. Immunohistochemistry (IHC) had been used to help in distinction. We studied two markers (stathmin-1 and CD147) to demonstrate whether they have diagnostic/ prognostic assist. Sixty seven USMT are studied. Age, follow up, and recurrence/metastasis data were collected. Representative slides were stained and Histologic score (HS) calculated as stain intensity (SI) X percentage of positive tumor cells (PP). Results were grouped as low expression (LE) and high expression (HE); then correlated to tumor types, and risk of recurrence/ metastasis. Statistical analysis $(\mathrm{P}<0.05)$; Sensitivity, specificity, positive and negative predictive values and confidence intervals in diagnosing ULMS were calculated. Stathmin-1 HS ( $\mathrm{p}=0.000)$ and HE ( $\mathrm{p}=0.002)$ were different among groups. Same as for CD147 HS and HE (both $\mathrm{p}=0.000$ ), with a gradient increase from LM to STUMP to ULMS. Sensitivity, specificity, positive and negative predictive values and confidence intervals in diagnosing ULMS were as following: For stathmin-1 HS: $92 \%$; $20 \%$; $42 \%$; and $80 \%$ (CI= 44-96 \%). For Stathmin-1 HE: 80\%; $66 \%$; $60 \%$; and 84 \% (CI=66-94 \%). For CD147 HS: $85 \%$; $22 \%$; $41 \%$; and $69 \%$. For CD147 HE: $58 \%$; $49 \%$; $42 \%$; and $65 \%$ (CI= 45-80\%), respectively. Recurrence / metastasis were documented in 6 cases (4 ULMS; 2 STUMP) with follow up ranging from 6 months to 102 months. 5 tumors had stathmin-1 HE (p=0.099); 2 had CD147 HE $(\mathrm{p}=0.393)$ in the primary tumors. STMN1 and CD147 are helpful diagnostic tests for USMT sub-typing, especially for ULMS. Gradient increase of expression from LM, to STUMP, to ULMS may indicate a role in malignant transformation in USMT, and in increased risk of recurrences/metastasis.
\end{abstract} 1; CD147.

KEY WORDS: Leiomyoma; Leiomyosarcoma; Smooth muscle tumors of uncertain malignant potential (STUMP); Stathmin-

\section{INTRODUCCIÓN}

Uterine smooth muscle tumors are a group of neoplasms that are the most common mesenchymal tumors of the female genital tract. Although all of these tumors originate from smooth muscle cells, they consist of different types according to behavior, including benign leiomyoma, malignant leiomyosarcoma, and intermediate group of tumors called smooth muscle tumors of undetermined malignant potential (STUMP). Pre-operative differential diagnosis of USMT is difficult as they produce similar clinical symptoms and even radiological studies cannot distinguish between them accurately. Thus, definite diagnosis is reliant on post-operative histopathological evaluation, which can also have limitations in some difficult cases. Immunohistochemical methods were tried recently as a surrogate measure in distinction between those tumors. In the current study, we aim to look for immunohistochemcial expression of two of the recently studied markers (stathmin1 and CD147) among uterine smooth muscle tumors resected at our institution, and to demonstrate whether such markers maybe a diagnostic aid of different types of USMT.

\section{MATERIAL AND METHOD}

Cases \& tissues. Following Institutional Ethics Committee and Review Board approval at our institution, cases were collected from Hospital histopathology Database during the last 10 years. A total of 67 cases of USMT were included

\footnotetext{
${ }^{1}$ Department of Pathology, Faculty of Medicine, University of Jordan, Amman, Jordan.

${ }^{2}$ Department of Pathology, Faculty of Medicine, Balqa Applied University, Al-Salt, Jordan.

Funding/ Support Statement: This study was supported by the Scientific Research Deanship at the University of Jordan/ Amman, Jordan.
} 
(20 ULM, 21 STUMP, and 26 ULMS). The selected tumors were previously classified based on World Health Organization (Tavassoli \& Devilee, 2003) and Stanford histological guidelines (Bell et al., 1994). Inclusion criteria were uterine mass resection specimens, with evidence of smooth muscle origin by at least one confirmatory IHC stain like Smooth Muscle Actin (SMA) or h-caldesmon. Distinction between STUMP and ULMS was based on Stanford histological criteria (Bell et al.). Other types of mesenchymal uterine lesions were excluded.

Histopathology reports of the cases were retrieved for collection of histopathological features. Review of electronic medical records was performed to retrieve information regarding clinical follow up and documented recurrence or metastatic disease for cases with follow up. Follow up was considered present with post- operative gynecology department clinic visits or reported post-op imaging studies. Recurrence and or metastatic disease were only considered present by a documented clinical note, radiological reports, or histopathology reports during follow up.

IHC. For each case, H\&E microscopic slides were reviewed and corresponding tissue blocks were retrieved for selection of representative tissue blocks for stathmin-1 and CD147 IHC according to standard manufacturers' protocols. Two tissue sections, each of $4 \mathrm{~mm}$ thickness were cut from formalin-fixed, paraffin-embedded tissue blocks of the selected tumors for staining. Rabbit mono-clonal antibodies for Stathmin (clone AR441; Dako Cytomation, Carpinteria, CA, USA) and for CD147 (clone 6F11; Ventana, Tucson, AZ, USA) were used and were stained as follows: After deparaffinization and hydration, sections were pretreated in microwave $\left(95^{\circ} \mathrm{C}, 15\right.$ $\mathrm{min}$ ) in $10 \mathrm{mM}$ citrate buffer ( $\mathrm{pH}$ 6.0) for antigen retrieval. After the quenching of endogenous peroxidase activity, sections were reacted with the Stathmin antibody (Prediluted in TRIS, $\mathrm{pH} 7.4$, containing $<0.1 \%$ sodium azide) for $20 \mathrm{~min}$, and CD147 antibody (Prediluted in TRIS, pH 7.4, containing $<0.1 \%$ sodium azide) for $15 \mathrm{~min}$ at room temperature. The sections were processed with Super Sensitive TM Polymer-HRP IHC Detection System (BioGenex; Fremont, California, USA) according to the manufacturer's instructions.

Results were then interpreted and scored by two pathologists independently blinded to type of tumor and using Olympus light microscope. Only membranous stain for CD147 and cytoplasmic stain for stathmin-1 was regarded positive. Quantitative analysis of the stains was done according to validated scoring protocols from the literature (Chen \& Yang, 2008; Mills et al., 2013); the staining was evaluated using a semi-quantitative system where both stain intensity (SI) and percentage of positive tumor cells (PP) is considered. SI was graded as 0 (no stain); 1 (weak); 2 (moderate); and 3 (strong), and PP as 0 (no stain); $1(<50$ $\%)$; to 2(>50\%). Histologic score (HS) for each antibody separately was then calculated as the average product of SI and $\mathrm{PP}$ on 5 random high power fields at 200x magnification, in cases with discordant scoring by the scorers, the average of scores, rounded to nearest integer, was considered for statistical analysis. Accordingly, $\mathrm{HS}=0$ was considered negative, and HS from 1-6 as positive. HS $\leq 3$ was defined as low expression and $>3$ as high expression.

Statistical analysis. Was performed using the Statistical Package for Social Sciences software version 20 (IBM Corp., Armonk, NY, USA). Statistical significance was determined by Fisher's exact test and Chi-square analysis for categorical variables and ANOVA for ordinal variables. $\mathrm{P}$ value $<0.05$ was considered statistically significant. Sensitivity, specificity, positive predictive values, negative predictive values with confidence intervals for reaction to each antibody in predicting ULMS diagnosis was calculated by positivity and high expression using Vassarstats Program (http:// www.vassarstats.net/clin1.html).

\section{RESULTS}

Clinical characteristics. Patient ages at diagnosis ranged from 32 to 53 years (mean for $L M=42$; STUMP $=41.3$ years; and ULMS $=45.2$ years). The follow up period (FUP) ranged from 6 months to 102 months (mean for $\mathrm{LM}=26$ months; STUMP $=39.3$ months; and ULMS $=34.5$ months). Follow up was documented in 53 cases (including all LM $(n=20)$, all STUMP $(n=21)$, and for 11 ULMS cases. Out of the followed up STUMP and ULMS (33 cases), a total of 6 cases (4 ULMS, 2 STUMP) had documented recurrence/ metastasis during follow up. Thus, the incidence of recurrence/ metastasis for our STUMP and ULMS cases with follow up was $9.5 \%$ and $36.3 \%$, respectively. Sites of recurrence/metastasis were intra-uterine in one (1 STUMP), intra-abdominal in 4 (4 ULMS), and perianal in one case (1 STUMP).

IHC results. For stathmin-1 IHC staining, out of $20 \mathrm{LM}$ cases, 4 were completely negative, 12 showed LE, while only 4 displayed HE (20\%). 10/21 STUMP cases ( $\approx 48 \%)$ showed HE, while 7 had LE, and 4 were completely negative. Regarding the ULMS cases, 2 cases were negative, 3 had LE, while 21 out of the 26 cases had HE $(\approx 81 \%)$, see Figure 1. Mean stathmin-1 (HS) was 2.0 in LM; 3.4 in STUMP; and 4.9 in ULMS ( $\mathrm{SD} \pm 1.89,2.25$, and 1.20, respectively. There was a significant difference between different tumor types, with a gradient increase in stathmin HS form LM, to STUMP, to ULMS ( $\mathrm{p}=0.000$ between groups) (Difference 

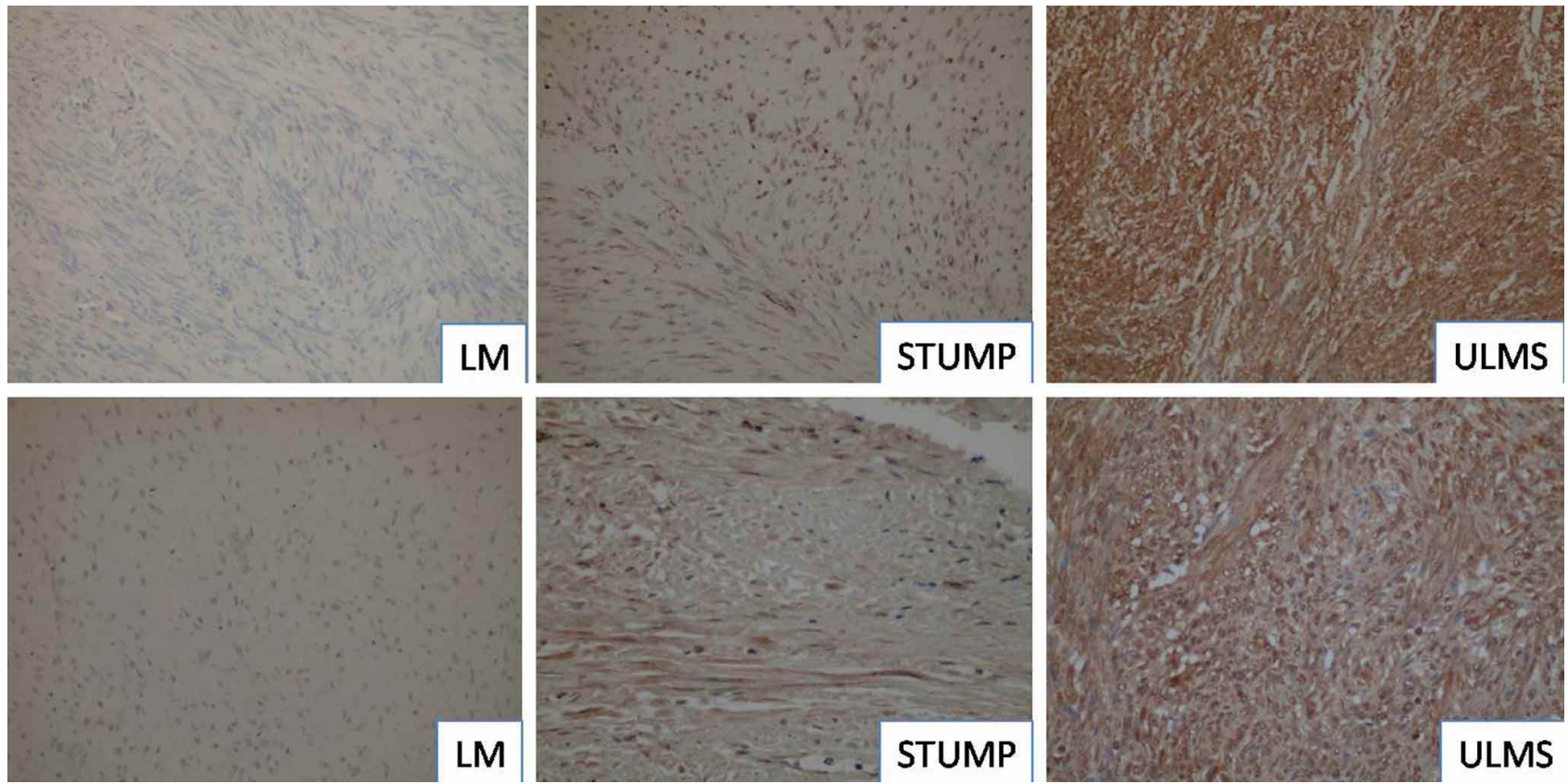

Fig. 1. IHC results in a leiomyoma (LM), smooth muscle tumor of undetermined malignant potential (STUMP), and a leiomyosarcoma (ULMS). Stathmin-1 (upper panel) and CD147 (lower panel) expression in LM (negative), STUMP (low expression), and in a ULMS (high expression) $(100 \mathrm{x})$.

between LM and ULMS $\mathrm{p}=0.000$; between LM and STUMP $\mathrm{p}=0.091$; and between STUMP and ULMS p=0.069).

In addition, tumor type was associated with the level of expression $(\mathrm{P}=0.002$ between groups) $\mathrm{jjj}$ (Difference between LM and ULMS $\mathrm{p}=0.003$; between LM and STUMP $\mathrm{p}=0.408$; and between STUMP and ULMS p=0.09).

Regarding CD147, out of the 20 LM cases, 8 were completely negative, 6 had LE, and only 4 had HE (20\%). One case of STUMP was negative, 3 had LE, while 17 had HE $(\approx 81 \%)$. Regarding ULMS cases, 4 were totally negative, 7 had LE, while 15 had HE $(\approx 58 \%)$. Mean CD147 HS was 1.5 in LM, 4.43 in STUMP, and 3.7 in ULMS (SD \pm $1.5 ; 1.69$; and 2.30 , respectively. There was a significant difference between different tumor types, with a gradient increase in CD147 HS form LM, to STUMP, to ULMS ( $p=$ 0.000 between groups). (Difference between LM and ULMS $\mathrm{p}=0.001$; between LM and STUMP $\mathrm{p}=0.000$; and between
STUMP and ULMS p=0.468).

Level of CD147 expression was also significantly correlated with Tumor type ( $\mathrm{p}=0.000$ between groups); with a similar increase in expression form LM to STUMP to ULMS (Difference between LM and ULMS $\mathrm{p}=0.015$; between LM and STUMP p=0.000; and between STUMP and ULMS $\mathrm{p}=0.264$ ). In order to examine the relationship between Stathmin-1 and Cd147 expression among different cases and tumor types, paired samples T-test was used.

The above results are summarized in Table I.

For stathmin positive reaction, the sensitivity of stathmin positivity for ULMS was $92 \%$ (confidence interval 74-96 \%). however, the specificity was low $20 \%$ (CI=9-35 $\%)$.The positive predictive value for ULMS diagnosis was $42 \%$ (CI= 29-55\%), while the negative predictive value was $80 \%(\mathrm{CI}=44-96 \%)$ (Table II).

Table I. Stathmin-1 and CD147 Immunohistochemical expression among different tumor types.

\begin{tabular}{|c|c|c|c|c|c|c|c|c|c|c|c|c|}
\hline \multirow[t]{2}{*}{ Tumor type } & \multicolumn{6}{|c|}{ CD147 HS } & \multirow[t]{2}{*}{ P value } & \multicolumn{3}{|c|}{ CD147 EL } & \multirow[t]{2}{*}{$\mathrm{P}$ value } & \multirow[t]{2}{*}{ Total } \\
\hline & 0 & 1 & 2 & 3 & 4 & 6 & & $\mathrm{Neg}$ & LE & $\mathrm{HE}$ & & \\
\hline LM & 8 & 2 & 6 & 0 & 4 & 0 & .000 & 8 & 8 & 4 & .000 & 20 \\
\hline STUMP & 1 & 0 & 2 & 1 & 8 & 9 & & 1 & 3 & 17 & & 21 \\
\hline ULMS & 4 & 1 & 4 & 2 & 4 & 11 & & 4 & 7 & 15 & & 26 \\
\hline Total & 13 & 3 & 12 & 3 & 16 & 20 & & 13 & 18 & 36 & & 67 \\
\hline
\end{tabular}

$\mathrm{LM}=$ leiomyoma; STUMP= smooth muscle tumor of uncertain malignant potential; ULMS= uterine leiomyosarcoma; HS= histologic score; EL: expression level; $\mathrm{Neg}=$ negative stain. $\mathrm{P}$ value $<0.05$ is significant using one way ANOVA and post Hoc multiple comparisons. 
ABU SHAHIN, N.; AL-KHADER, A.; ALSAYED, M.; ALJARRAH, D. \& KHADER, M. Differential expression, diagnostic, and prognostic significance of stathmin-1 and CD147 in various uterine smooth muscle tumors. Int. J. Morphol., 37(1):311-318, 2019.

Table II. Test parameters calculated for Stathmin-1 using HS and High expression levels for a diagnosis of ULMS.

\begin{tabular}{|c|c|c|c|c|c|c|}
\hline \multirow{3}{*}{ Parameter } & \multicolumn{3}{|c|}{ Stathmin-1 } & \multicolumn{3}{|c|}{ Stathmin-1 high expression } \\
\hline & \multirow{2}{*}{$\begin{array}{c}\text { Estimated } \\
\text { Value } \%\end{array}$} & \multicolumn{2}{|c|}{$95 \% \mathrm{CI}$} & \multirow{2}{*}{$\begin{array}{c}\text { Estimated } \\
\text { Value } \%\end{array}$} & \multicolumn{2}{|c|}{$95 \% \mathrm{CI}$} \\
\hline & & Lower limit & Upper limit & & Lower limit & Upper limit \\
\hline Prevalence & 33.7 & 23.6 & 45.5 & 38.8 & 27.4 & 51.5 \\
\hline Sen sitivity & 92.3 & 73.4 & 98.7 & 80.8 & 60.01 & 92.7 \\
\hline Specificity & 19.6 & 10.3 & 33.5 & 65.9 & 49.3 & 79.4 \\
\hline Positive & 84.4 & 73.9 & 91.3 & 52.2 & 39.8 & 64.4 \\
\hline Negative & 15.6 & 8.7 & 26.0 & 47.8 & 35.6 & 60.2 \\
\hline PPV & 36.9 & 25.5 & 49.9 & 60 & 42.2 & 75.6 \\
\hline False Positive & 63.1 & 50.2 & 74.4 & 40 & 24.3 & 57.8 \\
\hline NPV & 83.3 & 50.9 & 97.1 & 84.4 & 66.5 & 94.1 \\
\hline False Negative & 16.6 & 29.4 & 49.1 & 15.6 & 5.9 & 33.5 \\
\hline
\end{tabular}

CI: Confidence Interval; PPV: positive predictive value; NPV: negative predictive value.

The detection of high level of stathmin expression (HS $>3$ ) in predicting ULMS diagnosis showed a sensitivity of $80 \%$ (CI=60-93\%), and specificity of $66 \%(\mathrm{CI}=49-79$ $\%)$. The PPV was $60 \%(\mathrm{CI}=42-76 \%)$, and NPV was $84 \%$ $(\mathrm{CI}=66-94 \%)$.

For CD147 positive reaction, the sensitivity of CD147 positivity for ULMS was $85 \%$ (confidence interval 64-95\%), the specificity was low $22 \%$ ( $\mathrm{CI}=11-38 \%)$. The positive predictive value for ULMS diagnosis was $41 \%$ (CI= 27-55\%), while the negative predictive value was $69 \%$ (CI= 39-90\%).
The detection of high level of CD147 expression $(\mathrm{HS}>3)$ in predicting ULMS diagnosis showed a sensitivity of $58 \%$ (confidence interval $38-76 \%$ ), the specificity was 49 $\%$ (CI=33-65\%).The positive predictive value for ULMS diagnosis was $42 \%$ (CI= 25-59\%), while the negative predictive value was $65 \%$ (CI= 45-80\%). Refer to Table III.

Out of the 47 STUMP and ULMS cases, recurrent disease and/or metastasis were documented in 6 cases (4 ULMS and 2 STUMP). Out of these, 5 had HE of stathmin- $1(\mathrm{p}=0.099)$, while 2 cases had HE of CD147 ( $\mathrm{p}=0.393$ ) in the primary uterine tumors.

Table III. Test parameters calculated for CD147 using HS and High expression levels for a diagnosis of ULMS.

\begin{tabular}{|c|c|c|c|c|c|c|}
\hline \multirow{3}{*}{ Parameter } & \multicolumn{3}{|c|}{ CD147 } & \multicolumn{3}{|c|}{ CD1 47 high expression } \\
\hline & \multirow{2}{*}{$\begin{array}{c}\text { Estimated } \\
\text { Value \% }\end{array}$} & \multicolumn{2}{|c|}{$95 \% \mathrm{CI}$} & \multirow{2}{*}{$\begin{array}{l}\text { Estimate d } \\
\text { Value } \%\end{array}$} & \multicolumn{2}{|c|}{$95 \% \mathrm{CI}$} \\
\hline & & Lower limit & Upper limit & & Lower limit & Upper limit \\
\hline Prevalence & 38.8 & 27.4 & 51.5 & 38.8 & 0.27 .4 & 51.5 \\
\hline Sen sitivity & 84.6 & 64.3 & 95.0 & 57.7 & 37.2 & 76.0 \\
\hline Specificity & 22.0 & 11.1 & 38.0 & 48.8 & 33.2 & 64.6 \\
\hline Positive & 80.6 & 68.8 & 88.9 & 53.7 & 41.2 & 65.8 \\
\hline Negative & 19.4 & 11.1 & 31.2 & 46.3 & 34.2 & 58.8 \\
\hline PPV & 40.7 & 27.9 & 54.9 & 41.7 & 26.0 & 59.1 \\
\hline False Positive & 59.3 & 45.1 & 72.1 & 58.3 & 40.9 & 74.0 \\
\hline NPV & 69.2 & 38.9 & 89.7 & 64.5 & 45.4 & 80.2 \\
\hline False Negative & 30.8 & 10.4 & 61.1 & 35.5 & 19.8 & 54.6 \\
\hline
\end{tabular}

CI: Confidence Interval; PPV: positive predictive value; NPV: negative predictive value.

Table IV. Stathmin-1 and CD147 Immunohistochemical expression among STUMP and ULMS tumors with recurrence/ metastasis. Pearson Chi square test.

\begin{tabular}{|c|c|c|c|c|c|c|c|c|c|c|c|c|c|}
\hline \multirow[b]{2}{*}{ Rec/mets } & & \multicolumn{6}{|c|}{ stathmin.HS } & \multirow[t]{2}{*}{ Total } & \multirow[t]{2}{*}{$\mathrm{P}$ value } & \multicolumn{3}{|c|}{ LE } & \multirow[t]{2}{*}{$\mathrm{P}$ value } \\
\hline & & 0 & 1 & 2 & 3 & 4 & 6 & & & Neg & $\mathrm{HS} \leq 3$ & $\mathrm{HS}>3$ & \\
\hline \multirow{4}{*}{ Total } & no & 11 & 2 & 8 & 6 & 6 & 11 & 44 & .409 & 9 & 18 & 17 & .109 \\
\hline & yes & 0 & 0 & 1 & 0 & 2 & 3 & 6 & & 0 & 1 & 5 & \\
\hline & & 11 & 2 & 9 & 6 & 8 & 14 & 50 & & 9 & 19 & 22 & \\
\hline & & \multicolumn{6}{|c|}{ CD 147.HS } & Total & $\mathrm{P}$ value & & LE & & $P$ value \\
\hline \multirow[t]{3}{*}{ Rec/mets } & & 0 & 1 & 2 & 3 & 4 & 6 & & & Neg & $\mathrm{HS} \leq 3$ & $\mathrm{HS}>3$ & \\
\hline & no & 11 & 2 & 8 & 2 & 11 & 10 & 44 & .643 & 11 & 12 & 21 & .522 \\
\hline & yes & 1 & 0 & 3 & 0 & 1 & 1 & 6 & & 1 & 3 & 2 & \\
\hline Total & & 12 & 2 & 11 & 2 & 12 & 11 & 50 & & 12 & 15 & 23 & \\
\hline
\end{tabular}

Rec/mets: recurrence or metastasis; LE: level of expression; HS: Histologic score; Neg.: negative stain. P value $<0.05$ is significant using. 
The difference was not statistically significant, however, between the tumor types (For Stathmin-1, $\mathrm{p}=0.326$ for positivity; $\mathrm{p}=0.595$ for HS; $\mathrm{p}=0.276$ for HE. As for CD147, $\mathrm{p}=0.617$ for positivity; Fisher's exact test 0.511 ; $\mathrm{p}=$ 0.08 for HS; and $\mathrm{p}=0.119$ for HE). Results are summarized in Table IV.

\section{DISCUSSION}

USMT encompass a large group of gynecological tumors ranging from those with favorable outcome (LM), to the highly aggressive ULMS, and in between these 2 extremes are tumors with borderline or intermediate behavior called STUMP. The most reliable method of distinction is still post-operative histopathological examination. This is due to the fact that Clinical presentation of USMT is similar and non specific typically causing menorrhagia, and abdominal/pelvic pain (Ip et al., 2010). Moreover, Pre-operative Imaging techniques like computed tomography and magnetic resonance imaging are not competent in distinction in many cases (Sato et al., 2014). A sonographic- guided fine needle biopsy as a diagnostic tool had been described in literature (Barbazza et al., 1997), however, results were controversial and not reproducible. Intra-operative frozen section examination is similarly of limited diagnostic value for USMT, as the features used to diagnose malignancy in smooth muscle tumors are very difficult to ascertain due to freezing artifact (El-Bahrawy \& Ganesan, 2014).

Subtyping of USMT is very significant due to the great diversity of clinical behavior and patient morbidity and mortality among those tumors. While LMs are considered the most common female benign tumors, with nil risk of malignant transformation, ULMS are aggressive neoplasms with high rates of recurrence and dismal prognosis (Tavassoli $\&$ Devilee).

The malignant behavior of USMT had been determined by a set of histopathological features called Stanford criteria (Bell et al.) that include: diffuse moderateto severe nuclear atypia; mitotic count of $\geq 10 / 10$ High Power Fields; and Tumor Coagulative Necrosis. At least two criteria are required for a diagnosis of ULMS. Those criteria were then adopted by the WHO for diagnostic purposes (Tavassoli \& Devilee).

Immuno histochemical stains (IHCs) as an ancillary diagnostic tool of USMT were used in literature. All USMT share in common the expression of smooth muscle markers such as desmin, H-caldesmon, and Smooth Muscle Actin (SMA). They are usually distinct from other types of uterine mesenchymal tumors such as endometrial stromal sarcomas and epitheloid perivascular neoplasms (PEComas) by being negative for other markers like CD10 and HMB-45, respectively (Ip et al.).

IHC markers had been previously attempted to assist in differentiating between a ULMS and a uterine LM. A variety of such markers had previously been evaluated, including p21, p27, p53, p16, IMP3, Ki-67, and fascin (O'Neill et al., 2007; Chen \& Yang; Fadare et al., 2011; Mills et al.). Varying degrees of efficacy in that context had been determined, however, they generally lack specificity as independent markers.

The aim of this study was to explore the utility of stathmin and CD147 as diagnostic and possibly prognostic markers of uterine ULMS by establishing its IHC reactivity in 3 different subtypes of USMTs.

Stathmin-1 (also known as oncopro-tein 18), is a cytoplasmic phosphoprotein that regulates microtubules motion during mitosis and interphase (Belletti \& Baldassarre, 2011) hence its importance in oncogenesis. Stathmin-1 alterations had been recently emphasized in different types of cancers, for instance, Stathmin-1 overexpression maybe a negative prognostic factor in both ovarian and endometrial carcinomas, and may have diagnostic utility in cervical and adnexal intraepithelial neoplasia (Wik et al., 2011; Howitt et al., 2013). Stathmin expression is also a significant indicator of activation of the oncogenic phosphatidylinositol 3-kinase-AKT-mammlian target of rapamycin pathway (PI3K-AKT-mTOR) pathway, a pathway proposed to be centrally associated with smooth muscle proliferation and highly activated in both uterine and extra uterine leiomyosarcoma (Hernando et al., 2007). Animal studies using mice carrying homologous deletions in an endogenous negative regulator of that pathway developed a range of abdominal smooth muscle proliferations including LM and aggressive ULMS (Hernando et al.); and that constitutive activation of P13K-Akt-mTOR pathway was only found in ULMS. That finding was later documented in human uterine ULMS as well; and up regulation of the pathway in smooth muscle tumors was actually assessed by gene expression profiling (Crabtree et al., 2009).

CD147 (also known as Basigin, or EMMPRIN), is a transmembrane glycoprotein and a member of the immunoglobulin super family (Muramatsu \& Miyauchi, 2003). The molecular features of CD147 determines its many roles in human cells, including transport of nutrients, leukocyte migration, induction of matrix metalloproteinase's, vision, spermatogenesis and other physiological phenomena (Muramatsu \& Miyauchi). It also plays significant roles in 
the pathogenesis of various diseases, including cancer (Grass et al., 2014). CD147 was found to be over expressed in a broad range of human malignant tumors (Kanekura \& Chen, 2010); and may be an unfavorable prognostic marker as it promotes invasive properties, proliferation, and survival of tumor cells (Grass et al.), and decreased overall survival in many types of cancer (Bovenzi et al., 2015); including breast cancer, ovarian cancer, colorectal cancer, and lung cancer. Moreover, CD147 as a functional biomarker may become attractive target for anticancer therapies. It had been previously examined in uterine smooth muscle neoplasms, and its expression was proposed as a potential diagnostic and prognostic marker in patients with leiomyosarcoma (ULMS) (Ozler et al., 2014). In the same study, CD147 expression positively correlated with Ki67 expression and mitotic index.

Our results showed a significant correlation between stathmin-1 expression and type of tumor, with a gradient increase in stathmin (HS) form LM, to STUMP, to ULMS (Pearson Chi square $=0.009)$. Most LM tested were either negative $(6 / 20 ; 30 \%)$ or showing low expression $(10 / 20 ; 50$ $\%$ ) of stathmin. However, Stathmin had low specificity as 4 out of 20 LM displayed high expression (20\% of LM). As for ULMS, $81 \%$ of the studied cases had high expression level for Stathmin, while only 2 cases were completely negative for it $(7.7 \%)$. Interestingly, STUMP cases displayed an intermediate reactivity between that of LM and ULMS (47.6 $\%$ had high expression).

Similarly, there was a statistically significant increase of CD147 expression from LM, to STUMP, to ULMS ( $\mathrm{p}=$ 0.006). Moreover, $8 \mathrm{LM}$ were completely negative for CD147 $(40 \%)$ and another 8 cases showed only low expression (40 $\%$ ), while only 1 STUMP (4.8\%) and 4 ULMS (15.4\%) had no reaction. High expression of CD147 was also significantly correlated with ULMS type $(\mathrm{p}=0.002)$.

The mean follow up period of the study was 39.3 months for STUMP group; and 34.5 months for ULMS group. During which, 6 cases (4 ULMS and 2 STUMPs) had documented recurrence or metastatic disease. Of those, 5 cases $(83.3 \%)$ showed high expression for stathmin $(\mathrm{p}=0.109)$, while 2 cases had high expression of CD147 ( $\mathrm{p}=0.522)$.

Apparently, correlation was not statistically significant between neither of stathmin-1 or CD147 (HS) and recurrence/metastasis (Pearson Chi2 $=0.409$ and 0.643 ), nor with level of stathmin-1 or CD147 expression ( $\mathrm{p}=0.643$ and 0.522). However, an interesting finding was that all four ULMS cases that had documented recurrence had positive and even high expression level of stathmin-1 (100\%) in the primary tumors. Three cases were additionally positive for CD147 and one was negative $(75 \%)$.
The results of the current study reveal relatively high sensitivity of stathmin-1 and CD147 expression (92\% and $84 \%$, respectively) in predicting a diagnosis of ULMS among USMTs, with statistical evidence of high negative predictive values ( $80 \%$ and $69 \%$, respectively). One drawback, however, is their low specificity (20\% and 22 $\%$, respectively). Interestingly, there is a statistically significant correlation between both markers' expression results $(\mathrm{Chi} 2=0.019)$ but not the expression level of both markers $(p=0.29)$. In addition, the correlation was even more significant in cases with recurrence/metastasis $(p=0.003)$, raising the thought of a potential role of such markers in carcinogenesis or aggressive behavior of those tumors.

Previous similar studies showed comparable results to current study; one study (Allen et al., 2015) documented $100 \%$ sensitivity of STMN1 expression for ULMS. However, the specificity was only $55 \%$. The NPV and PPV for ULMS were $100 \%$ and $52 \%$ respectively. Another disadvantage of stathmin-1 was that non-USMTs that were studied showed at least focal Stathmin-1 immunoreactivity.

Ozler et al. studied CD147 expression in USMT and found that CD147 was strongly expressed in $81.8 \%(\mathrm{n}=18)$ of ULMS, significantly higher than that of other uterine smooth muscle tumor types $(\mathrm{p}=0.000)$. However, high CD147 expression was found in only one LM variant and one STUMP. Furthermore, CD147 expression was correlated with Ki67 expression (Spearman's rank $=0.466, \mathrm{p}<0.05$ ) and mitotic index (Spearman's rank $=0.554, \mathrm{p}<0.05)$, respectively.

A major disagreement between the results of those studies and ours is that our study showed a higher expression in STUMP cases; with an increasing gradient of expression from LM, to STUMP, to ULMS cases, indicating a possible role of these markers in the carcinogenesis and malignant transformation of smooth muscle tumors.

Study limitations may include the small sample sizes, which is mainly due to the fact that STUMP and ULMS are relatively rare disorders. In addition, the expression of Stathmin-1 and CD147 was not examined in other types of mesenchymal tumors of the uterus.

CONCLUSIONS. TMN1 and CD147 are sensitive and potentially useful markers (especially when combined) in sub typing of USMT. Although neither is specific for diagnostic purposes, both markers have high negative predictive value for ULMS. The high negative predictive value for ULMS may offer some diagnostic utility in differentiating between atypical variants of LM and STUMP in one hand form ULMS in the other, since the absence of 
immunoreactivity in a presumed ULMS is a powerful dispute against such a diagnosis. Furthermore, Stathmin-1 and CD147 expression levels may also have prognostic value for patients with ULMS, as a potential predictor of risk of recurrence/ metastatic disease.

Finally, the presence of an increasing gradient of expression from LM, to STUMP, to ULMS cases may indicate a role of these markers in carcinogenesis and malignant transformation of USMT.

ABU SHAHIN, N.; AL-KHADER, A.; ALSAYED, M.; ALJARRAH, D. \& KHADER, M. Expresión diferencial, diagnóstico y significado de pronóstico de stathmin-1 y cd147 en diferentes tumores del músculo liso uterino. Int. J. Morphol., 37(1):311-318, 2019.

RESUMEN: Los tumores del músculo liso uterino (USMT, por sus siglas en inglés) son tumores ginecológicos comunes y de comportamiento distinto; incluyendo: leiomioma (ULM), leiomiosarcoma (ULMS) y tumores de músculo liso de potencial maligno indeterminado (STUMP). La distinción preoperatoria es difícil, por lo que el diagnóstico se basa en la histopatología. La inmunohistoquímica (IHQ) se había utilizado para ayudar en la distinción. Estudiamos dos marcadores (stathmin-1 y CD147) para demostrar si había efecto diagnóstico / pronóstico. Se estudiaron 67 USMT. Se recopilaron los datos de edad, seguimiento y recurrencia / metástasis. Las muestras representativas se tiñeron y la puntuación histológica (HS) se calculó como la intensidad de la tinción (IS) x porcentaje de células tumorales positivas (PP). Los resultados se agruparon como expresión baja (EB) y expresión alta (EA); luego se correlacionaeon con los tipos de tumores y el riesgo de recurrencia / metástasis. Análisis estadístico ( $\mathrm{P}<0,05$ ); se calcularon la sensibilidad, la especificidad, los valores predictivos positivos y negativos y los intervalos de confianza en el diagnóstico de ULMS. Stathmin-1 HS $(p=0,000)$ y HE $(p=0,002)$ fueron diferentes entre los grupos. Igual que para CD147 HS y HE (ambos $p=0,000$ ), con un aumento de gradiente de LM a STUMP a ULMS. La sensibilidad, la especificidad, los valores predictivos positivos y negativos y los intervalos de confianza en el diagnóstico de ULMS fueron los siguientes: Para stathmin-1 HS: $92 \%$; $20 \%$; $42 \%$; y $80 \%$ (IC $=44-96 \%$ ). Para Stathmin-1 HE: $80 \%$; $66 \%$; $60 \%$; y $84 \%$ (IC = 66-94 \%). Para CD147 HS: $85 \%$; $22 \%$; $41 \%$; y el $69 \%$. Para CD147 HE: $58 \%$; 49 $\% ; 42 \%$; $65 \%(\mathrm{IC}=45-80 \%)$, respectivamente. La recurrencia / metástasis se documentaron en 6 casos (4 ULMS; 2 STUMP) con un seguimiento que osciló entre 6 meses y 102 meses. Cinco tumores tenían stathmin-1 HE ( $\mathrm{p}=0,099)$; dos tenían CD147 HE ( $\mathrm{p}=0,393)$ en los tumores primarios. STMN1 y CD147 son pruebas de diagnóstico útiles para la subclasificación de USMT, especialmente para ULMS. El aumento en el gradiente de la expresión de LM, a STUMP, a ULMS puede indicar un papel en la transformación maligna en USMT y en un mayor riesgo de recurrencias / metástasis.

PALABRAS CLAVE: Leiomioma; Leiomiosarcoma; Tumores de músculo liso de potencial maligno incierto (STUMP); Stathmin-1; CD147.

\section{REFERENCES}

Allen, M. M.; Douds, J. J.; Liang, S. X.; Desouki, M. M.; Parkash, V. \& Fadare, O. An immunohistochemical analysis of stathmin 1 expression in uterine smooth muscle tumors: differential expression in leiomyosarcomas and leiomyomas. Int. J. Clin. Exp. Pathol., 8(3):2795801, 2015.

Barbazza, R.; Chiarelli, S.; Quintarelli, G. F. \& Manconi, R. Role of fineneedle aspiration cytology in the preoperative evaluation of smooth muscle tumors. Diagn. Cytopathol., 16(4):326-30, 1997.

Bell, S. W.; Kempson, R. L. \& Hendrickson, M. R. Problematic uterine smooth muscle neoplasms. A clinicopathologic study of 213 cases. Am. J. Surg. Pathol., 18(6):535-58, 1994.

Belletti, B. \& Baldassarre, G. Stathmin: a protein with many tasks. New biomarker and potential target in cancer. Expert. Opin. Ther. Targets, 15(11):1249-66, 2011.

Bovenzi, C. D.; Hamilton, J.; Tassone. P.; Johnson, J.; Cognetti, D. M.; Luginbuhl, A.; Keane, W. M.; Zhan, T.; Tuluc, M.; Bar-Ad, V.; MartinezOutschoorn, U. \& Curry, J. M. Prognostic indications of elevated MCT4 and CD147 across cancer types: a meta-analysis. Biomed. Res. Int., 2015:242437, 2015.

Chen, L. W. \& Yang, B. Immunohistochemical analysis of p16, p53, and Ki-67 expression in uterine smooth muscle tumors. Int. J. Gynecol. Pathol., 27(3):326-32, 2008.

Crabtree, J. S.; Jelinsky, S. A.; Harris, H. A.; Choe, S. E.; Cotreau, M. M.; Kimberland, M. L.; Wilson, E.; Saraf, K. A.; Liu, W.; McCampbell, A. S.; Dave, B.; Broaddus, R. R.; Brown, E. L.; Kao, W.; Skotnicki, J. S. Abou-Gharbia, M.; Winneker, R. C. \& Walker, C. L. Comparison of human and rat uterine leiomyomata: identification of a dysregulated mammalian target of rapamycin pathway. Cancer Res., 69(15):61718, 2009.

El-Bahrawy, M. \& Ganesan, R. Frozen section in gynaecology: uses and limitations. Arch. Gynecol. Obstet., 289(6):1165-70, 2014.

Fadare, O.; Renshaw, I.; Olson, S. J. \& Liang, S. X. The phosphatidylinositol 3' kinase-Akt-mammalian target of rapamycin pathway in smooth muscle tumors of the uterus: selected protein expression patterns and their clinicopathologic implications. Int. J. Gynecol. Pathol., 30(3):244$51,2011$.

Grass, G. D.; Dai, L.; Qin, Z.; Parsons, C. \& Toole, B. P. CD147: regulator of hyaluronan signaling in invasiveness and chemoresistance. Adv. Cancer Res., 123:351-73, 2014.

Hernando, E.; Charytonowicz, E.; Dudas, M. E.; Menendez, S.; Matushansky, I.; Mills, J.; Socci, N. D.; Behrendt, N.; Ma, L.; Maki, R. G.; Pandolfi, P. P. \& Cordon-Cardo, C. The AKT-mTOR pathway plays a critical role in the development of leiomyosarcomas. Nat. Med., 13(6):748-53, 2007.

Howitt, B. E.; Nucci, M. R.; Drapkin, R.; Crum, C. P. \& Hirsch, M. S. Stathmin-1 expression as a complement to p16 helps identify highgrade cervical intraepithelial neoplasia with increased specificity. Am. J. Surg. Pathol., 37(1):89-97, 2013.

Ip, P. P.; Tse, K. Y. \& Tam, K. F. Uterine smooth muscle tumors other than the ordinary leiomyomas and leiomyosarcomas: a review of selected variants with emphasis on recent advances and unusual morphology that may cause concern for malignancy. Adv. Anat. Pathol., 17(2):91$112,2010$.

Kanekura, T. \& Chen, X. CD147/basigin promotes progression of malignant melanoma and other cancers. J. Dermatol. Sci., 57(3):149-54, 2010.

Mills, A. M.; Ly, A.; Balzer, B. L.; Hendrickson, M. R.; Kempson, R. L.; McKenney, J. K. \& Longacre, T. A. Cell cycle regulatory markers in uterine atypical leiomyoma and leiomyosarcoma: immunohistochemical study of 68 cases with clinical follow-up. Am. J. Surg. Pathol., 37(5):634-42, 2013.

Muramatsu, T. \& Miyauchi, T. Basigin (CD147): a multifunctional transmembrane protein involved in reproduction, neural function, 
inflammation and tumor invasion. Histol. Histopathol., 18(3):981-7, 2003.

O'Neill, C. J.; McBride, H. A.; Connolly, L. E. \& McCluggage, W. G. Uterine leiomyosarcomas are characterized by high p16, p53 and MIB1 expression in comparison with usual leiomyomas, leiomyoma variants and smooth muscle tumours of uncertain malignant potential. Histopathology., 50(7):851-8, 2007.

Ozler, A; Evsen, M. S.; Turgut, A.; Sak, M. E.; Tunc, S. Y.; Agacayak, E.; Alabalik, U.; Basaranoglu, S.; Keles, A. N. \& Gul, T. CD147 expression in uterine smooth muscle tumors, and its potential role as a diagnostic and prognostic marker in patients with leiomyosarcoma. J. Exp. Ther. Oncol., 10(4):325-30, 2014

Sato, K.; Yuasa, N.; Fujita, M. \& Fukushima, Y. Clinical application of diffusion-weighted imaging for preoperative differentiation between uterine leiomyoma and leiomyosarcoma. Am. J. Obstet. Gynecol., 210(4):368.e1-368.e8, 2014.

Tavassoli, F. A. \& Devilee, P. World Health Organization Classification of Tumours. Tumours of the Breast and Female Genital Organs. $3^{\text {rd }}$ ed. Lyon, International Agency for Research on Cancer Press, 2003.

Wik, E.; Trovik, J.; Raeder, M. B.; Mannelqvist, M.; Mauland, K. K.; Oyan, A. M.; Kalland, K. H.; Akslen, L. A. \& Salvesen, H. B. Gene expression signature characterized by PI3Kinase activation and Stathmin overexpression validates to identify aggressive disease and a potential for PI3Kinase-inhibitors in endometrial carcinomas. Cancer Res., 71(8 Suppl.):Abstract nr. 330, 2011.
Corresponding author:

Nisreen Abu Shahin, M.D.

Associate Professor of Pathology

Department of Pathology

Faculty of Medicine

University of Jordan

Queen Rania Street

Aljubaiha 11942

Amman

JORDAN

Email: n.abushahin@ju.edu.jo

Received: 15-08-2018

Accepted: 26-11-2018 